\title{
Reduction Kinetics of Fine Hematite Ore Particles in Suspension
}

\author{
ZHIYUAN CHEN (1), CHRISTIAAN ZEILSTRA, JAN VAN DER STEL, JILT SIETSMA, \\ and YONGXIANG YANG
}

\begin{abstract}
Suspension reduction kinetics of hematite ore particles at $1710 \mathrm{~K}$ to $1785 \mathrm{~K}$ was described by the Johnson-Mehl-Avrami-Kolmogorov model with Avrami exponent of 1.405. The apparent activation energy is $105.5 \mathrm{~kJ} \mathrm{~mol}^{-1}$ with the rate determining step of nucleation and growth. The reduction degree of the hematite at the endpoint is a linear function of temperature and the logarithmic oxygen potential of the reacting gas. A peak function of reaction rate constant with particle size has been verified in this work, and the maximum value of the reaction rate is located at around $85 \mu \mathrm{m}$ particle size. The influence of heat transfer on the reaction process has been evaluated. The results suggest that the heating-up process for large particles, $244 \mu \mathrm{m}$ particles, for instance, cannot be ignored. It can retard the reaction rate compared to small particles. Normally, the reaction rate constant decreases linearly with the increase of $\ln \left[p\left(\mathrm{O}_{2}\right)\right]$ of the reacting gas mixture. However, 95 vol pct $\mathrm{CO}_{2}$ in the reacting gas can accelerate the reaction rate of thermal decomposition of hematite due to the emissivity of $\mathrm{CO}_{2}$ gas. It results in a higher reaction rate of $110 \mu \mathrm{m}$ particles in $95 \mathrm{vol}$ pct $\mathrm{CO}_{2}$-containing gas than that in other less $\mathrm{CO}_{2}$-containing gases.
\end{abstract}

https://doi.org/10.1007/s11663-021-02269-5

(C) The Author(s) 2021

\section{INTRODUCTION}

HISARNA is an emerging and promising alternative ironmaking process, developed to reduce $\mathrm{CO}_{2}$ emissions. A smelting cyclone is used to melt and pre-reduce fine and un-agglomerated iron ore particles in HIsarna reactor. Fine ore and flux are injected in the smelting cyclone together with oxygen. The injected ore is intensely mixed with rising hot reducing gases which undergoes partial reduction and melting. The melt hits the water-cooled sidewalls of the cyclone section and flows down along the wall and into the liquid bath in the smelting reduction vessel (SRV) where the final reduction takes place. The ore in the cyclone section is pre-reduced to a degree of about 20 pct through thermal decomposition and reduction by the SRV gas. The

ZHIYUAN CHEN is with the Department of Materials Science and Engineering, Delft University of Technology, Mekelweg 2, 2628 CD Delft, The Netherlands and also currently with the Separation and Conversion Technology, Flemish Institute for Technological Research, 2400 Mol, Belgium. Contact e-mail: aha c@126.com, zhiyuan.chen@vito.be CHRISTIAAN ZEILSTRA and JAN VAN DER STEL are with the R\&D, Tata Steel in Europe, PO Box 10000 , 1970 CA IJmuiden, The Netherlands. JILT SIETSMA and YONGXIANG YANG are with the Department of Materials Science and Engineering, Delft University of Technology.

Manuscript submitted November 17, 2020; accepted June 23, 2021.

Article published online July 19, 2021. temperature of the melt is approximately $1723 \mathrm{~K}$. There are limited publications about the details of the reaction mechanism and kinetics and are the subject of the present research with High-temperature Drop Tube Furnace (HDTF).

In order to develop alternative ironmaking processes, experimental work has been done to explore the reduction kinetics of iron ore particles in suspension reduction in recent 10 years. ${ }^{[1-9]}$ Especially, the reduction of fine hematite particles has been studied at the temperature range from $1550 \mathrm{~K}$ to $1750 \mathrm{~K}$ in $\mathrm{CO}_{2}$ reaching atmospheres to support the development of the HIsarna process. ${ }^{[10]}$ It still needs more experimental work on the high-temperature suspension reduction kinetics, of which the temperature is higher than $1710 \mathrm{~K}$. At such temperature, the reduction products become half molten or fully melted. ${ }^{[9]}$ The effects of reaction temperature, gas composition, and particle size on the reaction kinetics need to be explored. Primarily, the reduction kinetics of ore strongly depend on its nature. Studies of iron ores with different resources and reacting at various conditions are very needed for a comprehensive knowledge of the reduction process.

Experimental work has been done in this work from $1710 \mathrm{~K}$ to $1785 \mathrm{~K}$ to provide the kinetic information of the reduction process of hematite particles at high temperature. The effect of gas composition, particle size, and temperature on the kinetics are discussed in detail. 


\section{EXPERIMENTAL}

The reduction of hematite particles was carried out in High-temperature Drop Tube Furnace (HDTF) in this study. The raw materials were provided by Tata Steel in IJmuiden. Most of the gangue and hematite phases are distributed in different particles. Therefore, the interaction between the gangue and hematite phases during the reaction can be ignored due to the laminar flow in the reactor. ${ }^{[1]}$ The average sizes of the ore particles are $67,85,110,142$ and $244 \mu \mathrm{m}$. The reaction times are from 72 to $1120 \mathrm{~ms}$. The details of the furnace were described in References 8 and 10 . Hematite particles fell through the hot zone in the furnace, reacting with the pre-heated reducing gas, and then were collected in the sealed chamber below the furnace. The reaction temperature range was from 1710 $\mathrm{K}$ to $1785 \mathrm{~K}$. The atmosphere is shown in Table I. The ambient pressure is $1 \mathrm{~atm}$.

The mass ratios of total iron $(\mathrm{TFe})$ and $\mathrm{Fe}^{2+}$ of the reacted samples were analyzed with ICP-AES (Inductively Coupled Plasma-Atomic Emission Spectrometry) and chemical titration, respectively. The titration method of $\mathrm{Fe}^{2+}$ follows the ASTM standard test method with the designation number of D 3872-05 (2005). The phase composition of the collected samples was detected by semi-quantitative XRD (Bruker D8 Advance X-Ray Diffraction) analysis. The data from ICP-AES and titration are used for kinetic modeling. Non-linear curve fitting module in OriginPro 2015 and 1stOpt 7.0 (authorized to University of Science and Technology Beijing) were combined for kinetic modeling. Levenberg Marquardt method was adopted as the iteration algorithm in the modeling work.

\section{RESULTS AND DISCUSSION}

\section{A. Reduction Degree}

The reduction degree $R$ of hematite ore is defined as the ratio of mass loss of oxygen to the total initial mass of oxygen in $\mathrm{Fe}_{2} \mathrm{O}_{3}$ in the ore. It was employed in this work to calculate the value of $R$ from the experimental data of titration and ICP-AES measurement:

$$
R=\frac{1}{3} \frac{\mathrm{Fe}^{2+} \text { (mass pct) }}{\mathrm{TFe} \text { (mass pct) }}
$$

Equation [1] is specifically applied for the reduction of $\mathrm{Fe}_{2} \mathrm{O}_{3}$ up to $\mathrm{FeO}$. Here, $\mathrm{FeO}$ is the very final product which can be produce with the assigned experimental conditions in this work. For hematite, $R=0 \mathrm{pct}$, for magnetite $R=11$ pct and for wustite $R=33.3$ pct. The value of $R$ can also be obtained from the phase composition:

$$
R=\frac{100 \%}{48} \frac{\frac{160}{2}\left[\frac{3}{232} \mathrm{Fe}_{3} \mathrm{O}_{4} \text { (mass pct) }+\frac{1}{72} \mathrm{FeO} \text { (mass pct) }\right]+\mathrm{Fe}_{2} \mathrm{O}_{3} \text { (mass pct) }-100}{\left.\frac{3}{464} \mathrm{Fe}_{3} \mathrm{O}_{4} \text { (mass pct) }+\frac{1}{144} \mathrm{FeO} \text { (mass pct) }+\frac{1}{160} \mathrm{Fe}_{2} \mathrm{O}_{3} \text { (mass pct }\right)}
$$

Phase composition is estimated from the XRD results. The depth of X-ray detection is from 2 to $20 \mu \mathrm{m}$, so that the information in the core of the particles could be missed in the XRD pattern. Therefore, as Figure 1 shows, the reduction degree calculated from XRD is gradually higher than the value from chemical analysis with increasing value of $R$. It implies that the reduction is a topochemical reaction.

The most common kinetic analysis contains two steps: (1) To get the values of rate constants $(k)$ from each batch of data independently; (2) To get activation energy from the fitting of $k-T$ relationship with Arrhenius equation. The fitting results from the first step were usually reported in the literatures as parts of the final kinetic analysis results, although, strictly speaking, they could not be. In order to obtain reliable results, a global fitting method was adopted in the modeling for the whole 23 batches of experiments. The fitting results could not be the best one for a specific batch of experiment data, but it is the optimized result for the whole. In the fitting process, the reaction rate constant was defined as:

$$
k=A \exp \left(-\frac{\Delta E}{R_{\mathrm{g}} T}\right)
$$

where $A$ is the pre-exponential factor in $\mathrm{s}^{-1}, \Delta E$ is the apparent activation energy in $\mathrm{J} \mathrm{mol}^{-1}, R_{\mathrm{g}}$ is gas constant and $T$ is the temperature in $\mathrm{K}$. The relationship between the reaction rate constant and particle size has been suggested to be a peak function. ${ }^{[11]}$ It means that the reaction rate constant of large particles could be higher than the small particles in this specific case. Moreover, the reaction rate constant was suggested to be an inverse relationship with particle size when the particle diameter is larger than $85 \mu \mathrm{m}$, for the particular iron ore tested in this study. This trend will be verified in the present work with more experiments at different temperatures. Additionally, the relationship between reaction rate constant and the atmosphere will be discussed.

Our previous study proposed that the reaction rate controlling step of this reduction process is nucleation and growth. ${ }^{[1]}$ Johnson-Mehl-Avrami-Kolmogorov model (JMAK model) is suggested to be employed to describe the reduction process of the particle ${ }^{[12-14]}$.

$$
-\ln (1-\alpha)=(k t)^{n},
$$

where $\alpha$ is the reaction fraction, $k$ is the reaction rate constant, and $t$ is the residence time, $n$ is the Avrami exponent.

Equation [4] is employed to simulate the reduction kinetics of hematite particles, where the reaction fraction can be defined as the ratio of reduction degree to the reduction degree at the end of the reaction, $R_{\max }$ :

$$
\alpha=R / R_{\max }
$$

A statistical analysis shows that $R_{\max }$ is the function of reaction temperature and oxygen potential of the gas system (Figure 2): 
Table I. Atmospheres in the Experiments

\begin{tabular}{lcccc}
\hline Atmosphere & $\mathrm{CO}($ Vol Pct) & $\mathrm{CO}_{2}$ (Vol Pct) & $\mathrm{H}_{2}$ (Vol Pct) & $\mathrm{N}_{2}$ (Vol Pct) \\
\hline PCR2' & 45 & 55 & 0 & 0 \\
PCR4' & 5 & 95 & 0 & 0 \\
PCR2 & 35.58 & 31.73 & 4.81 & 27.88 \\
PCR4 & 4 & 66 & 1 & 29 \\
\hline
\end{tabular}

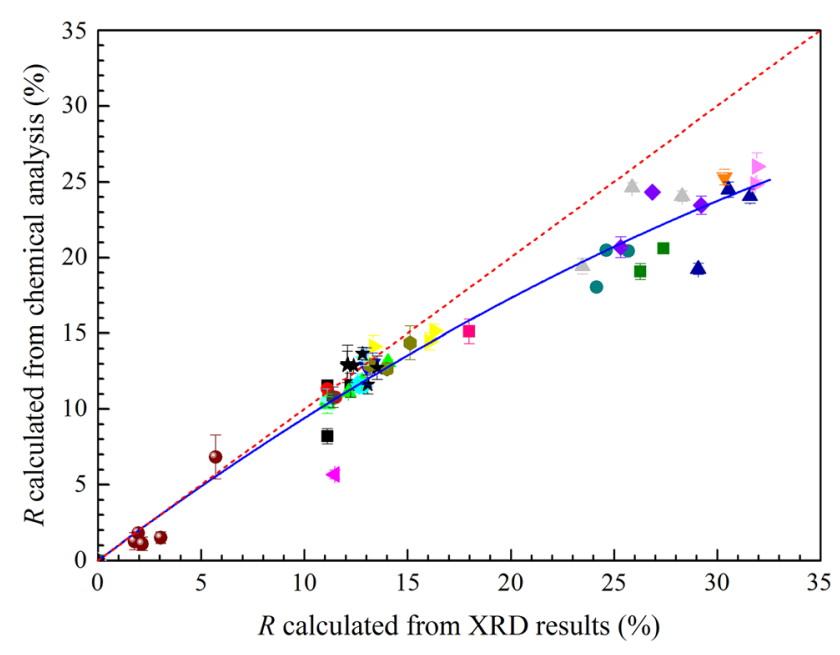

Fig. 1-Reduction degree of hematite ore particles in this work which is calculated from chemical analysis and XRD results. A parabola can represent this relationship. Different symbols here indicate data from different batches of experiments.

$$
\begin{aligned}
R_{\max }= & (-165 \pm 25)+(8.62 \pm 1.41) \times 10^{-2} T-(2.16 \\
& \pm 0.14) \ln p\left(\mathrm{O}_{2}\right)
\end{aligned}
$$

where the oxygen potential of the gas system is extracted from the equilibrium state of the gas mixture, $p\left(\mathrm{O}_{2}\right)$ is oxygen potential in atm. This equation can empirically predict the terminal reduction degree of hematite in the reaction.

For the JMAK model, Avrami exponent, $n$, is a crucial parameter. ${ }^{[15-17]}$ Usually, the value of $n$ is 4 for a three-dimensional nucleation and growth process in an infinite space. Yet, Alekseechkin ${ }^{[18]}$ pointed out that the Avrami exponent decreases with time from 4 to 1 in homogeneous nucleation and 3 to 0 in specific heterogeneous nucleation in a particle with finite size. Our previous calculation ${ }^{[11]}$ based on the surface/bulk nucleation and growth model of Villa and Rios ${ }^{[19]}$ also indicate that the reduction of particle size can result in the decrease of Avrami exponent in the JMAK model. Strictly speaking, for the particles with different sizes, the value of Avrami exponent used for JMAK model can be changed. While the value of Avrami exponent for all particles are assumed to be the same in this work, in the previous report, the value of Avrami exponent was set to be 4 for the limitation of the amount of data. In this work, JMAK models with Avrami exponent ranging from 0.5 to 4 were adopted for the fitting. As Figure 3 shows, the apparent activation energy increases with the decreasing Avrami exponent. The difference in the value of $\Delta E$ can be more than 5 times. The difference of $R^{2}$, the indicator of the quality of fitting, is tiny among the fitting results. Nevertheless, $R^{2}$ is a peak function of Avrami exponent. The optimized value of $n$ is 1.405 with highest value of $R^{2}$, which is selected for the kinetic analysis. In the global fitting, the apparent activation energy for all the experiments is chosen to be the same. Moreover, the pre-exponential factor for the particles with the same size and in the same atmosphere is the same. Figure 4 shows the analysis results with the JMAK model $(n=1.405)$. The value of apparent activation energy is estimated to be $105.5 \mathrm{~kJ} \mathrm{~mol}^{-1}$. The pre-exponential factors are listed in Table II.

\section{B. Effect of Temperature on the Reduction Process}

The Arrhenius equation is employed to describe the relationship between the reaction rate constant and temperature in this process. The value of $\Delta E$ in this work is lower than that in the report of Qu et al. ${ }^{[8,10]} \mathrm{It}$ is in that the reaction mechanism changes due to the temperature elevation. The difference in resources of raw materials could also contribute to the various kinetic mechanisms. There are a lot of activation energy data in the literature with the reaction temperature low than $1273 \mathrm{~K}$. The summarization from the recent reports ${ }^{[20,21]}$ indicated that the value of the activation energy varied from 33.3 to $139.2 \mathrm{~kJ} \mathrm{~mol}^{-1}$ for the reduction of $\mathrm{Fe}_{2} \mathrm{O}_{3}$ in $\mathrm{H}_{2}$ or $\mathrm{CO}$ containing atmospheres. The only comparable results in the similar high-temperature range are from the research group of Sohn. Their reports indicated that the activation energy of $\mathrm{H}_{2}$ or $\mathrm{CO}$ reduction of hematite particles was 214 and $231 \mathrm{~kJ} \mathrm{~mol}^{-1}$, respectively. ${ }^{[2,23]}$ Sohn et al. also reported the kinetic mechanism of magnetite concentrate at high temperature in the form of the JMAK model. The value of $n$ varies from $2^{[24,25]}$ to $0.56^{[26]}$ under different experimental conditions. Moreover, the $\Delta E$ of the reduction ranges from 180 to 463 $\mathrm{kJ} \mathrm{mol}^{-1} \cdot[24,25,27,28]$ The value of kinetic parameters highly depends on the structure of the reagent and the reaction conditions. ${ }^{[29,30]}$ For instance, Pourghahramani et $a l^{[31]}$ reported that introducing dislocations and defects into the mineral structure could reduce the activation energy of the reduction. Therefore, the reported value in this work is in reasonable range. 


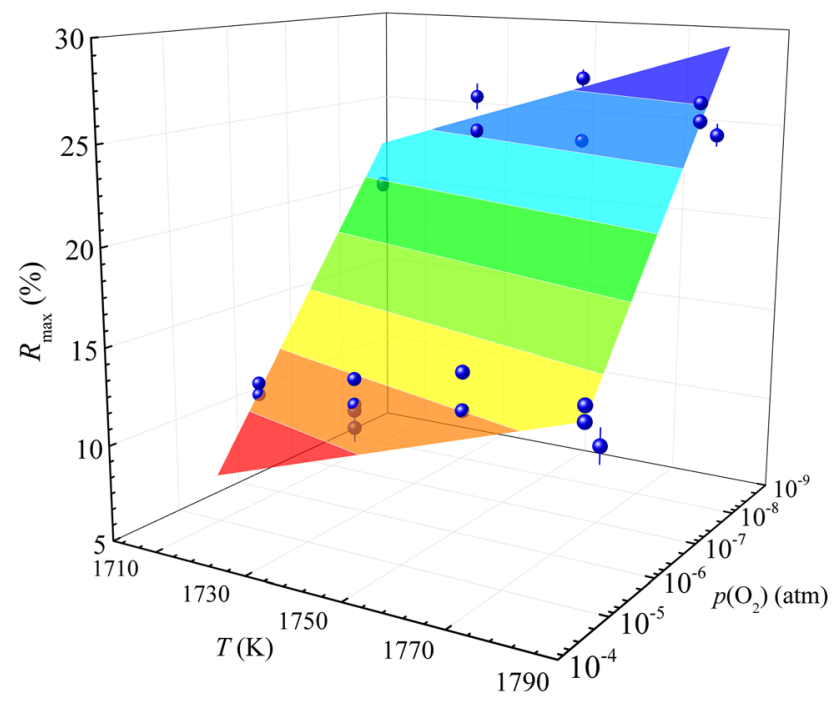

Fig. $2-R_{\max }$ as a function of reaction temperature and oxygen partial pressure.

\section{Effect of Heat Transfer on the Reduction Process}

Due to the global fitting needs to develop a balance among the errors of all batches of experimental data, one could find the deviation of the fitting curves from a part of the raw data. Nevertheless, it can be noted in Figure 4 that the deviation of the experimental data of $244 \mu \mathrm{m}$ particle from the modeling result is relatively significant. The four data points with $R^{2}$ around 0.73 in the two box charts with data in Figure 3 are corresponding to the experimental data of $244 \mu \mathrm{m}$ particle. On the one hand, the reduction degree of $244 \mu \mathrm{m}$ particle is much lower than the other particles. It results in a significant relative error of the experimental data. On the other hand, the extremely low values of $R^{2}$ also imply a deviation of the reaction process of $244 \mu \mathrm{m}$ particle from other particles. It is suspected to be the effect of heat transfer during the reaction. This will be discussed in the following sections.

Although the reduction is regarded as an isothermal reaction in the kinetic analysis, the heating process of hematite particles from room temperature to the reaction temperature needs a certain period of time when it is suddenly injected into the heating zone of the furnace. The heating-up time could be longer for the large particles, and the slow heating process can delay the reduction of hematite. In order to confirm this hypothesis, a simplified calculation was employed for the analysis of the heat transfer process of a hematite particle in terms of characteristic heating times.

Heat conduction was considered as the heat transfer mode within the particle. Convection and radiation were considered in the heat transfer in the $\mathrm{CO}_{2}$ atmosphere. The influence of the enthalpy change of chemical reactions is not considered during the calculation. The parameters in the calculation are listed in Table III. Especially, the surface emissivity of the ore and wall is a suggested value for chalcopyrite. ${ }^{[32]}$ With the assumption that the particles are spheres, the characteristic time of the three modes of heat transfer are as follows ${ }^{[33]}$ :

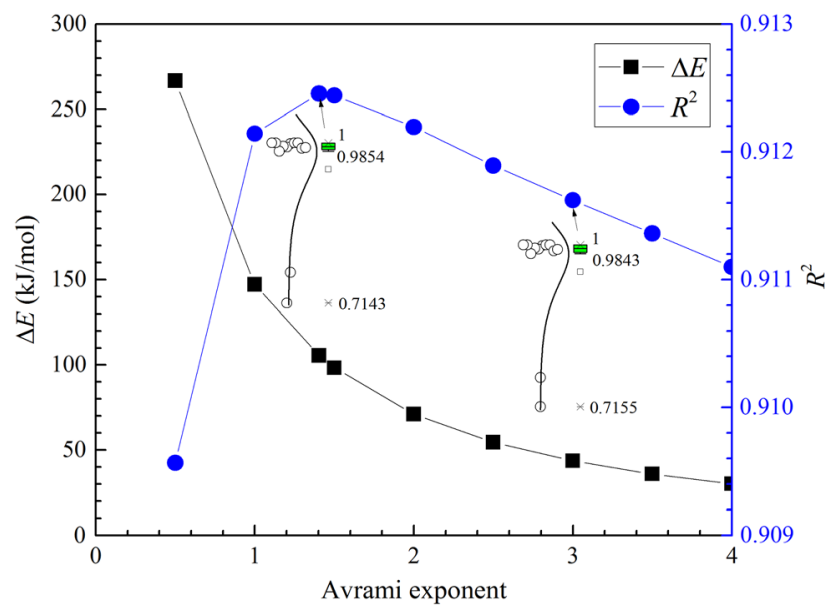

Fig. 3-Apparent activation energy and $R^{2}$ as the fitting results of JMAK model with various Avrami exponent, two box charts with data and Weibull distribution curves are attached inside.

Gas phase conduction:

$$
t_{\mathrm{c}}=\frac{\rho_{\mathrm{p}} C_{\mathrm{p}} d_{\mathrm{p}}^{2}}{6 N u \lambda_{\mathrm{g}}}
$$

Radiation:

$$
t_{\mathrm{r}}=0.42 \frac{\rho_{\mathrm{p}} d_{\mathrm{p}} C_{\mathrm{p}}}{12 \varepsilon_{\mathrm{p}} \sigma T_{\mathrm{w}}^{3}}\left(\text { where } \frac{T_{\mathrm{p}}^{0}}{T_{\mathrm{w}}}=0.2\right)
$$

Conduction inside the particle:

$$
t_{\mathrm{c}, \mathrm{p}}=\frac{\rho_{\mathrm{p}} C d_{\mathrm{p}}^{2}}{20 \lambda_{\mathrm{p}}}
$$

At the characteristic time, the temperature of one particle (or the geometrical center of the particle in Eq. [9]) has been raised to $1251 \mathrm{~K}$, which is 0.632 times of the difference between its initial temperature and ambient temperature.

Figure 5 shows the calculation results which show that the characteristic time of internal conduction of the particle is always lower than $70 \mathrm{~ms}$, which is much lower than the other two characteristic times. Hence temperature distribution within the particle during the reaction can be treated as uniform, since heat transfer resistance is located outside the particle. The figure also shows that the principal mode of heat transfer from the ambiance to the small particles is conduction, and to the large particles is radiation. Generally, the characteristic time of heat transfer from ambience to the particle varies from less than $100 \mathrm{~ms}$ to more than $1000 \mathrm{~ms}$ with the increase of particle size. For instance, the value of $t_{\mathrm{c}}$ is as high as $583 \mathrm{~ms}$ for $500 \mu \mathrm{m}$ particle. This value is longer than the residence time of it in HTDF. It indicates that the reduction of $244 \mu \mathrm{m}$ particles is non-isothermal, and error of the prediction results of kinetic modeling, which is based on isothermal reactions. Besides, it verifies that the reduction of small particles $\left(d_{\mathrm{p}} \leq 142 \mu \mathrm{m}\right)$ can be simplified as an isothermal reaction in the present work. 


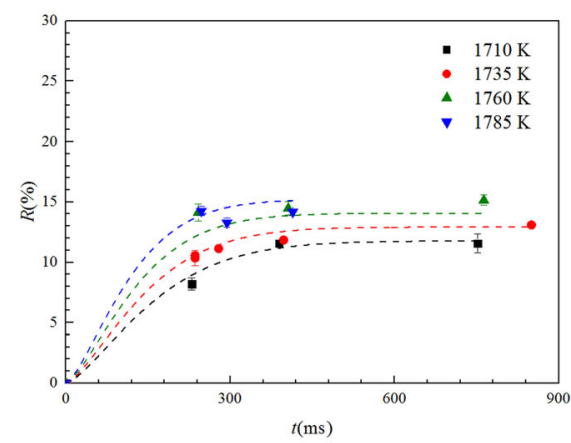

(a)

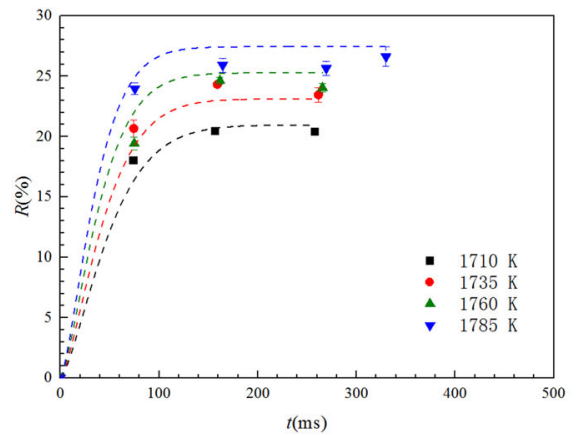

(d)

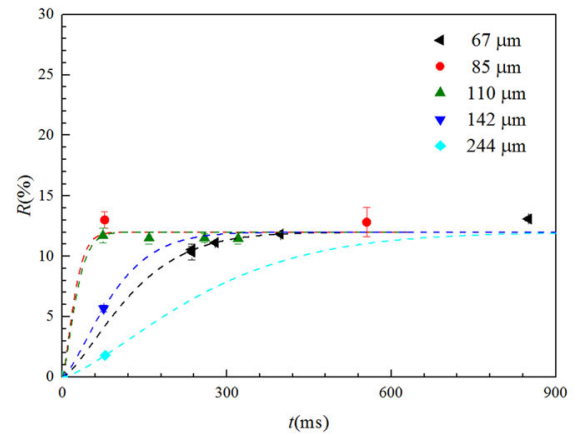

(g)

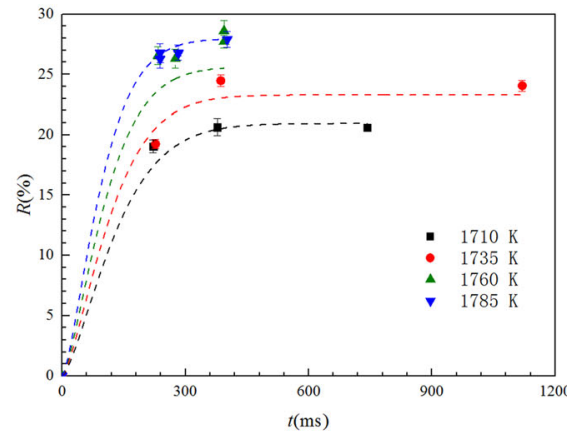

(b)

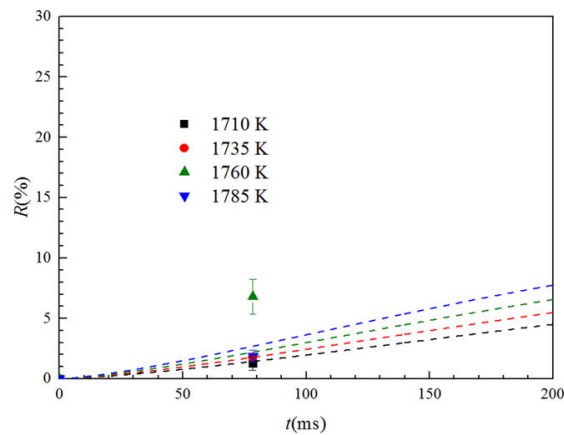

(e)

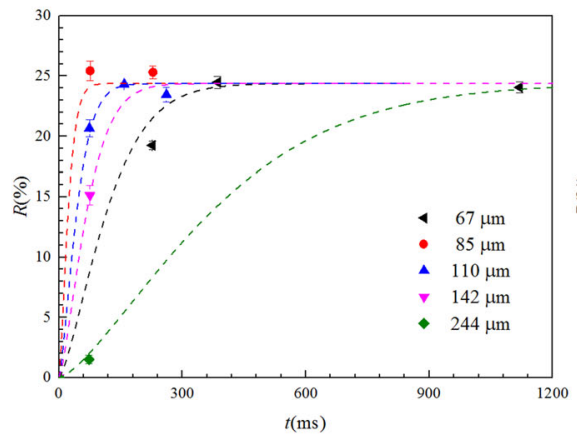

(h)

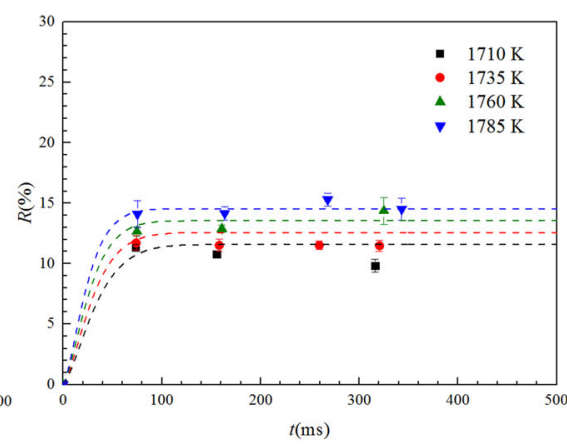

(c)

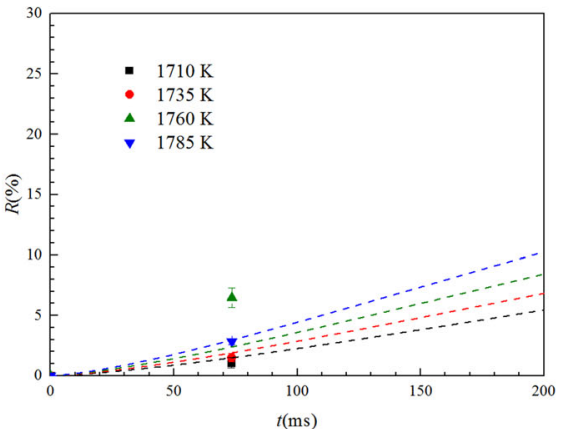

(f)

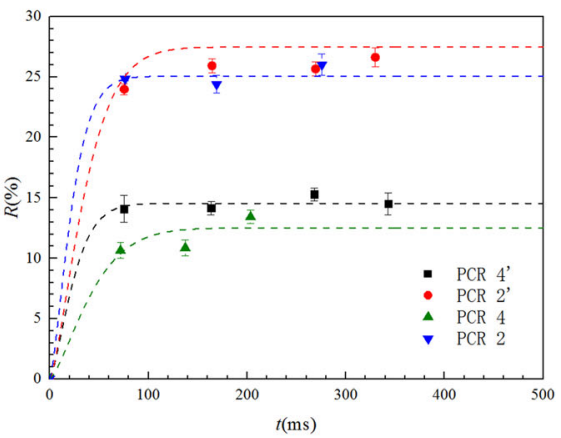

(i)

Fig. 4 -Fitting results of experimental results with JMAK model $(n=1.405)$ : $(a) 67 \mu$ m particle in PCR $4^{\prime}$ gas; $(b) 67 \mu \mathrm{m}$ particle in PCR2' gas; (c) $110 \mu \mathrm{m}$ particle in PCR 4' gas; (d) $110 \mu \mathrm{m}$ particle in PCR2' gas; (e) $244 \mu \mathrm{m}$ particle in PCR 4' gas; $(f) 244 \mu \mathrm{m}$ particle in PCR $4^{\prime}$ gas; $(g)$ particles in PCR4' gas at $1735 \mathrm{~K} ;(h)$ particles in PCR2' gas at $1735 \mathrm{~K}$; and $(i) 110 \mu \mathrm{m}$ particle in different gases at $1785 \mathrm{~K}$.

Table II. Pre-Exponential Factors $\left(\mathrm{s}^{-1}\right)$ in JMAK Model $(n=1.405, E=105.5 \mathrm{~kJ} / \mathrm{mol})$ as the Fitting Results

\begin{tabular}{lcccr}
\hline Atmosphere & $67 \mu \mathrm{m}$ & $85 \mu \mathrm{m}$ & $110 \mu \mathrm{m}$ & $142 \mu \mathrm{m}$ \\
\hline PCR4' $^{\prime}$ & $9294 \pm 814$ & $\geq 58,500^{*}$ & $44450 \pm 7140$ & $14120 \pm 1510$ \\
PCR2' & $11310 \pm 1060$ & $\geq 57,700^{*}$ & $30110 \pm 1950$ & $19370 \pm 2930$ \\
PCR4 & & $25510 \pm 6010$ & $5039 \pm 198$ \\
PCR2 & & $48180 \pm 30840$ & \\
\hline
\end{tabular}

*It is the lower limit of the pre-exponential factor

\section{Effect of Particle Size on the Reduction Process}

The effect of particle size on the reaction rate constant has been discussed in detail in our previous work, ${ }^{[11]}$ which reported that the reduction rate of the particles with particle size of $85 \mu \mathrm{m}$ reached the highest, while quadratic equations were adopted for the description of the effect of particle size on the reduction process at $1735 \mathrm{~K}$ :

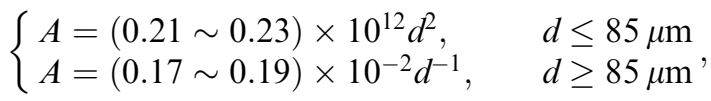


where the units of $A$ and $d$ are $\mathrm{s}^{-1}$ and $\mathrm{m}$, respectively. the particle size $d$ is in the range of 67 to $244 \mu \mathrm{m}$. It was suggested that, based on the JMAK model with Avrami exponent as 4, the theoretical equation for reaction rate was suggested to be an inverse proportional function of particle size when the particle size is larger than $85 \mu \mathrm{m}$. The original theoretical elaboration of this relationship is from the classical work of Mampel. ${ }^{[36]}$ It is noted that the experimental data were employed more in this work, covering the temperature from $1710 \mathrm{~K}$ to $1785 \mathrm{~K}$. Therefore, with a larger database and the same global fitting method, the Avrami exponent in the JMAK model was further optimized to be 1.405 in the present work, and the relationship of reaction rate constant and particle size was examined with more extensive data.

As Figure 6 demonstrates, the reaction rate constant of $110 \mu \mathrm{m}$ particle is higher than that of $67 \mu \mathrm{m}$ particle in the temperature range from $1710 \mathrm{~K}$ to $1786 \mathrm{~K}$. Kinetic Models for nucleation and growth process also indicates that the increasing particle size of "small", particles can facilitate reaction rate of them. ${ }^{[11]}$ It verifies that the reduction of hematite is rate-determined by the nucleation and growth process in this work. Furthermore, an empirical formula can be established for the particles with a size larger than $110 \mu \mathrm{m}$ :

$$
\begin{cases}A=(0.9 \pm 2.5) \times 10^{9} d^{-(2.2 \pm 0.5)}, & \text { for PCR2 } \\ A=(1.4 \pm 5.5) \times 10^{13} d^{-(4.2 \pm 0.8)}, & \text { for PCR4 }\end{cases}
$$

were, the units of $A$ and $d$ are $\mathrm{s}^{-1}$ and $\mathrm{m}$, respectively (Figure 7).

\section{E. Effect of Oxygen Partial Pressure on the Reduction Process}

Wang et al. ${ }^{[24,25]}$ proposed that the effect of gas on the reaction rate constant of magnetite concentrate can be described as:

$$
k \propto p_{\mathrm{H}_{2}}^{1 / 2}-\left(p_{\mathrm{H}_{2} \mathrm{O}} / K\right)^{1 / 2}
$$

where the units of $k$ and $p$ are $\mathrm{s}^{-1}$ and atm, respectively. Fan et $a l^{[37]}$ suggested that the reaction rate constant of magnetite concentrate has a linear relationship with the partial pressure of hydrogen and water vapor in the reacting gas. Their studies were in the environment of humidified hydrogen. Additionally, Post Combustion Ratio (PCR) is used in industrial practice, where the PCR of gas is defined as follows ${ }^{[10]}$ :

$$
\mathrm{PCR}=\frac{p\left(\mathrm{CO}_{2}\right)+p\left(\mathrm{H}_{2} \mathrm{O}\right)}{p\left(\mathrm{CO}_{2}\right)+p\left(\mathrm{H}_{2} \mathrm{O}\right)+p(\mathrm{CO})+p\left(\mathrm{H}_{2}\right)} \times 100 \%
$$

The test results of HIsarna experimental plant ${ }^{[38]}$ implies that, roughly, the reduction degree of the cyclone production has a linear relationship with the PCR value of the reacting gas. Similarly, $\mathrm{Qu}^{[10]}$ suggested in her thesis that the reaction rate constant of hematite as solid or solid-liquid-mixture particles follows a linear relationship with $p(\mathrm{CO})+p\left(\mathrm{H}_{2}\right)$ under her experimental conditions:

$$
k=A+B \frac{p(\mathrm{CO})+p\left(\mathrm{H}_{2}\right)}{p(\text { total })},
$$

where $p$ (total) is the pressure of the total gas, $A$ and $B$ are constant. There are different values for $A$ and $B$ in different atmospheres. The only exception is the reduction of solid-liquid-mixture particles of hematite in $\mathrm{H}_{2}-\mathrm{CO}-\mathrm{CO}_{2}-\mathrm{N}_{2}$ gas at $1650 \mathrm{~K}$. It can be noted that Eq. [14] is a specialized form of the effect of PCR value on the reaction rate constant. In the present work, the partial pressure of oxygen was introduced into the formula instead of PCR value. As Figure 8(a) shows, it is easy to infer a linear relation of $\mathrm{k}$ and $p\left(\mathrm{O}_{2}\right)$ for different atmospheres:

$\left\{k=-(0.084 \pm 0.006)-(0.0056 \pm 0.0003) \ln p\left(\mathrm{O}_{2}\right)\right.$, for gas - solid reaction $\left\{k=-(0.029 \pm 0.003)-(0.0019 \pm 0.0002) \ln p\left(\mathrm{O}_{2}\right)\right.$, for gas - mixture reaction

The same as the report of $\mathrm{Qu},{ }^{[10]}$ there is an exception to the data point, which is lower than the predicted value. Nevertheless, it can be realized that the effect of different gas compositions on the reaction rate constant can be summarized as the function of $p\left(\mathrm{O}_{2}\right)$. The same trends can be found in our study for the particles with an average size of 67 and $142 \mu \mathrm{m}$. The reaction rate constant decreases with the increase of $p\left(\mathrm{O}_{2}\right)$ for these reduction processes. However, there is an abnormal relationship between $k$ and $p\left(\mathrm{O}_{2}\right)$ for the reduction of $110 \mu \mathrm{m}$ particles. The following hypothesis is proposed, which could explain the unusual phenomenon of the reduction of $110 \mu \mathrm{m}$ particles: if the reduction rate of the ore particles is fast enough, the heating-up process can be one of the determining factors of the reaction rate. The following details are the support of this hypothesis.

It is known that the reduction of hematite ore is composed of two parts of reactions: thermal decomposition and gas reduction. ${ }^{[6,39]}$ Based on the published experimental data of $\mathrm{Qu},{ }^{[10]}$ the participation of the two reactions in the reaction process is estimated through her model. The illustration results are presented in Figure 9. It shows that the principal reaction is thermal decomposition at initial, and it accomplished within 200 ms. The rate of gas reduction is lower than the thermal decomposition at the beginning, while the gas reduction dominates the following process. The thermal decomposition time has also been evaluated for our samples. Figure 10 shows the kinetic data of thermal decomposition of hematite ore. It can be noted that the fast reaction accomplished within $70 \mathrm{~ms}$ at $1785 \mathrm{~K}$ in the $\mathrm{N}_{2}$ atmosphere. The reaction rate is comparable with the reaction rate of the same particles in PCR4' gas. A JMAK model with Avrami exponent of 1.405 was also employed to fit the experimental data. The modeling results show that the reaction rate constant is $32.7 \pm 7.1$ $\mathrm{s}^{-1}$, and the reduction degree of the ore at the terminal point is $12.3 \pm 0.4$ pct. It reconfirms that the reaction rate of thermal decomposition is high enough 
Table III. Parameters in Heating Process Estimation of Hematite Ore

\begin{tabular}{lll}
\hline Parameter & \multicolumn{1}{c}{ Symbol } & Value \\
\hline Density of Ore & $\rho_{\mathrm{P}}\left(\mathrm{kg} \mathrm{m}^{-3}\right)$ & 5240 \\
Heat Capacity of Ore & $C_{\mathrm{P}}\left(\mathrm{J} \mathrm{kg}^{-1} \mathrm{~K}^{-1}\right)$ & $1000^{[34]}$ \\
Conductivity of Ore & $\lambda_{\mathrm{P}}\left(\mathrm{W} \mathrm{m} \mathrm{K}^{-1}\right)$ & $1^{[34,35]}$ \\
Diameter of Ore & $d_{\mathrm{P}}(\mu \mathrm{m})$ & 30 to \\
Initial Temperature of Ore & $T_{\mathrm{P}}^{0}(\mathrm{~K})$ & 355 \\
Temperature of Tube/Ambience & $T_{\mathrm{w}}(\mathrm{K})$ & 1773 \\
Pressure & $P(\mathrm{~atm})$ & 1 \\
Nusselt Number & $\mathrm{Nu}$ & 2 \\
Surface Emissivity of Ore/Wall & $\varepsilon_{\mathrm{P}}$ & 0.5 \\
\hline
\end{tabular}

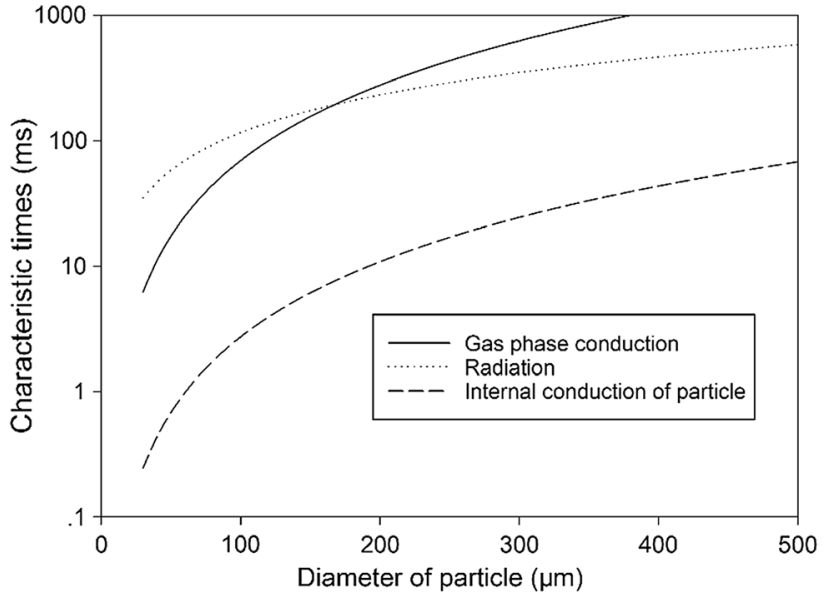

Fig. 5-Characteristic time of the heating-up process of particles with different sizes.

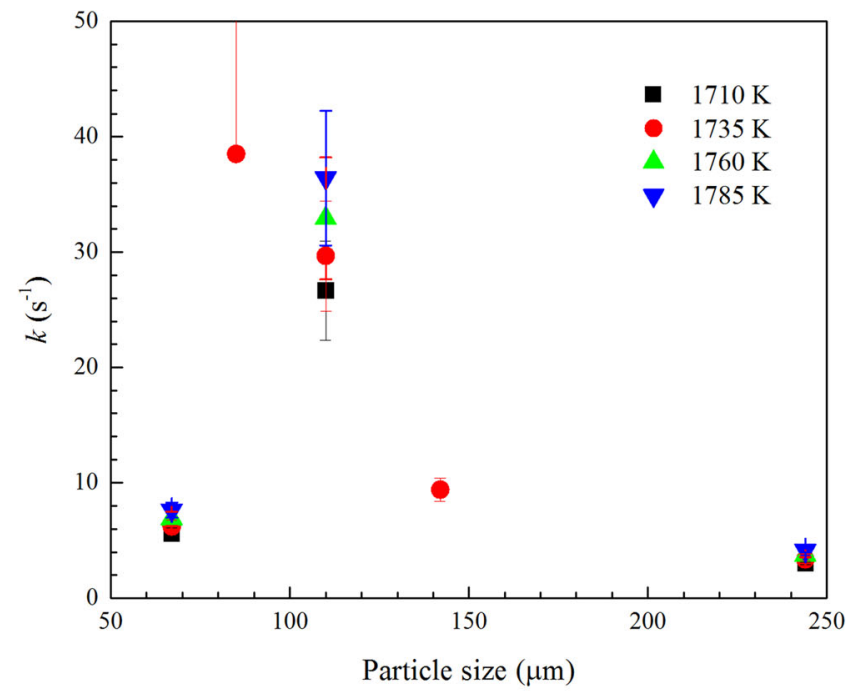

(a) comparing to the overall reaction rate. It also implies that the reduction process of hematite ore particles in PCR4' gas, or the atmosphere with low reducing potential, can be dominated by the thermal decomposition reaction.

Therefore, the inverse trends of the reaction rate of $110 \mu \mathrm{m}$ particles in Figure 8 are because of the character of thermal decomposition. Qu et al. ${ }^{[6]}$ observed that the equivalent reduction degrees and reduction degree of hematite in $\mathrm{CO}_{2}$ is higher than that in $\mathrm{Ar}$ and $\mathrm{N}_{2}$ in the thermal decomposition process. It is suggested to be the radiative properties of $\mathrm{CO}_{2}$ gas. ${ }^{[40]}$ The heat transfer in $\mathrm{CO} 2$ gas is more effective than that in Ar and N2. Due to the slower heat up process in Ar and N2 gases, the corresponding reduction rates are lower. Similarly, in our work, the reduction degree of hematite particles in pure $\mathrm{CO}_{2}$ at $1710 \mathrm{~K}$ can reach the same value of the ore in $\mathrm{N}_{2}$ gas and in $69.5 \mathrm{vol}$ pet $\mathrm{CO}_{2}+30.5$ vol pet $\mathrm{N}_{2}$ gas

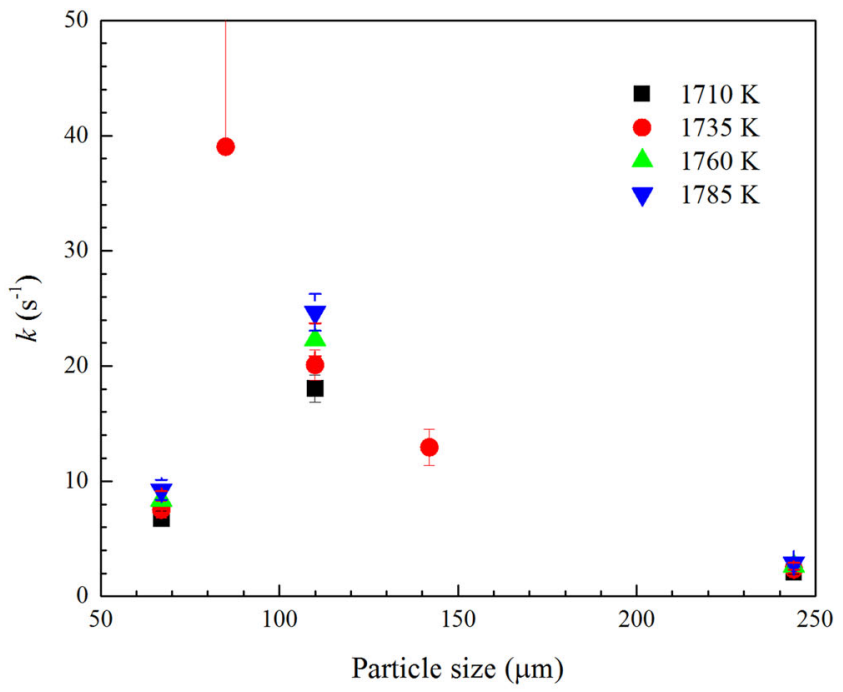

(b)

Fig. 6-Effect of particle size on the reaction rate constant in (a) PCR4' and (b) PCR2' atmospheres. 


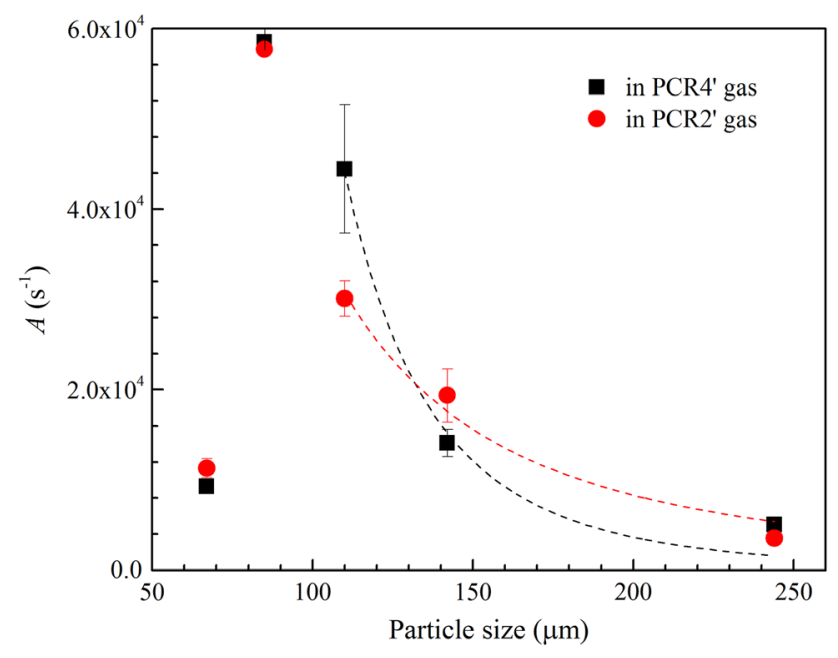

Fig. 7-Relationship between particle size and pre-exponential factor.

at $1785 \mathrm{~K}$. Moreover, Figure 10 also indicates that, although pure $\mathrm{CO}_{2}$ can effectively accelerate the heat transfer process, even as high as 69.5 vol pet of $\mathrm{CO}_{2}$ cannot significantly raise the reduction degree of ore in thermal decomposition. As shown in Figure 8(c), it can be noted that the reaction rate constants of hematite particles in PCR4' gas are higher than those in PCR2' gas for the $110 \mu \mathrm{m}$ particles. Yet, the value of $k$ decreases with the increase of $p\left(\mathrm{O}_{2}\right)$ in PCR2, PCR2' and PCR4 gases at $1785 \mathrm{~K}$ in sequence. The $\mathrm{CO}_{2}$ concentration in PCR4' gas is $95 \mathrm{vol} \mathrm{pct}$, and it in other gases is lower than $69.5 \mathrm{vol}$ pct. That implies that the effect of $\mathrm{CO}_{2}$ on the heating-up process of ore particles is less strong in the other three gases. Therefore, only the reaction of $110 \mu \mathrm{m}$ particles in PCR4' gas performs "abnormal" high reaction rate. It results in the different trend for $110 \mu \mathrm{m}$ particles in Figure 8. Besides, we have not discussed the reaction rate constants of $85 \mu \mathrm{m}$ and $244 \mu \mathrm{m}$ particles because of the large error bars of them.

\section{CONCLUSIONS}

The reduction kinetics of hematite ore particles at the temperature ranging from $1710 \mathrm{~K}$ to $1785 \mathrm{~K}$ has been investigated in this work.

(1) The reduction rate of hematite ore particles is determined by the nucleation and growth process during the reaction, which follows the JMAK model in the form of

$-\ln \left(1-\frac{R}{R_{\max }}\right)=-\left[A \exp \left(-\frac{105.5 \times 10^{3}}{R_{\mathrm{g}} T}\right) t\right]^{1.405}$.

(2) The effect of the partial pressure of the gas and the reaction temperature on the reduction degree of hematite ore particles at the terminal point is described by the following equations:

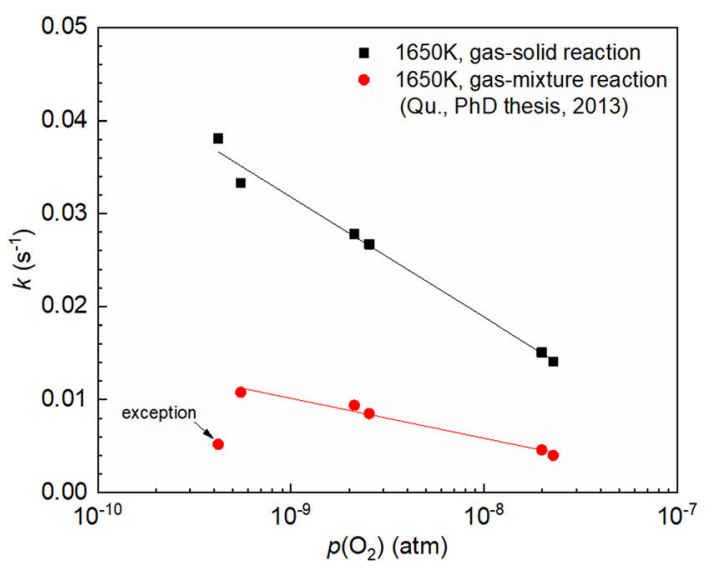

(a)

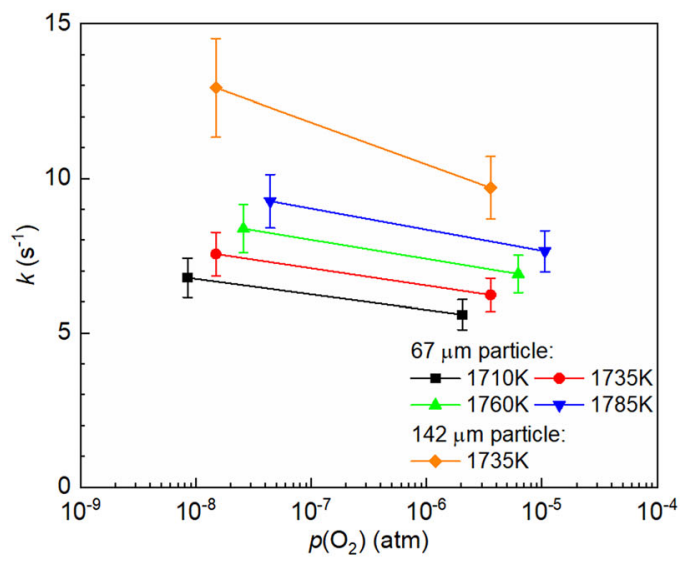

(b)

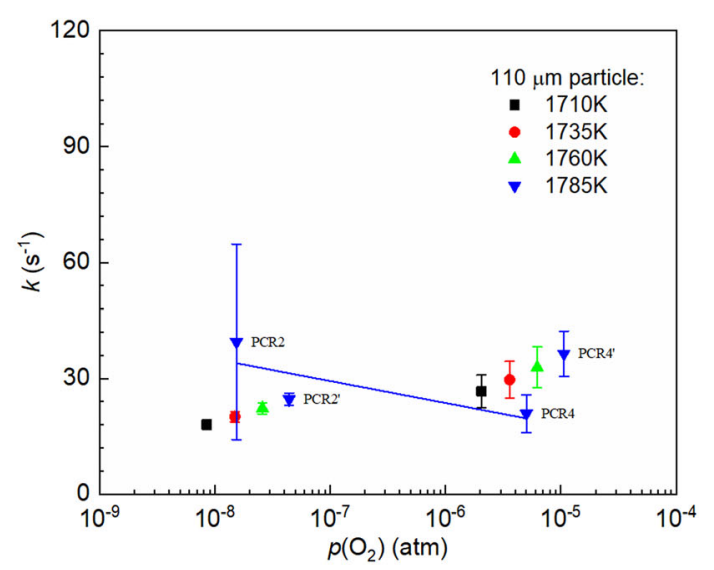

(c)

Fig. 8-Effect of partial pressure of oxygen on reaction rate constant for (a) experimental data in Ref. [10]; (b) the reaction of $67 \mu \mathrm{m}$ and $142 \mu \mathrm{m}$ particles; and $(c)$ the reaction of $110 \mu \mathrm{m}$ particles.

$$
\begin{aligned}
R_{\max }= & (-165 \pm 25)+(8.62 \pm 1.41) \times 10^{-2} T-(2.16 \\
& \pm 0.14) \ln p\left(\mathrm{O}_{2}\right)
\end{aligned}
$$

(3) The theoretical study results show that the ore particles can be treated as an uniform temperature body during the present study. The dominant heat transfer mode to heat up the particle turns from 


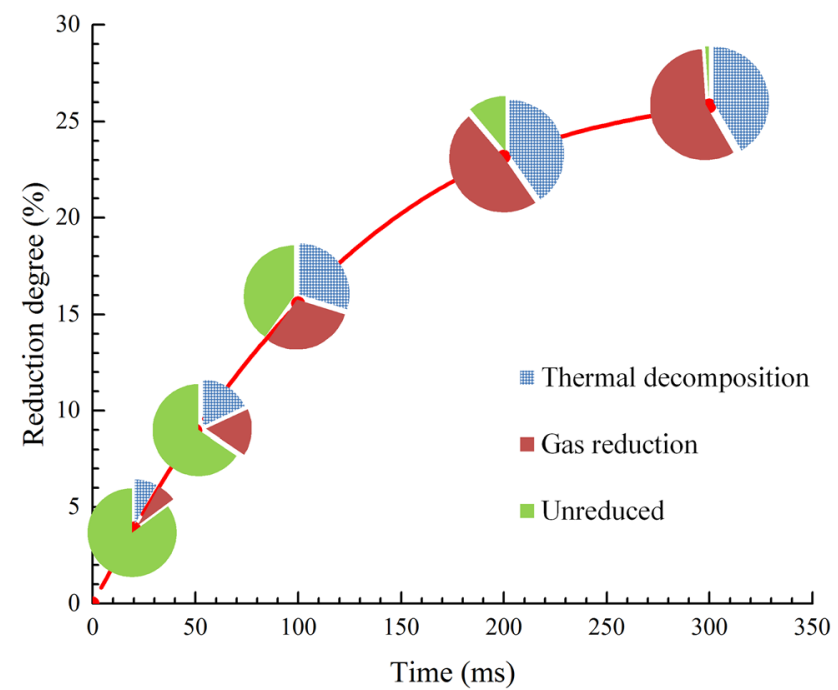

Fig. 9-Reaction process of hematite ore at $1750 \mathrm{~K}$ in gas with $\mathrm{CO}_{2}$ $=57.8 \mathrm{vol}$ pet and $\mathrm{CO}=42.2 \mathrm{vol}$ pet in Qu's work. ${ }^{[10]}$

radiation to gas phase conduction with the increase of particle size. Moreover, the heating-up process of large particles, extremely $244 \mu \mathrm{m}$ particles in this study, could have a negative effect on the reduction degree.

(4) It is indicated that the pre-exponential factor, $A$, is a peak function of reacting particle size, with a maximum value at around $85 \mu \mathrm{m}$. Moreover, the value of $A$ can be expressed as an exponential function of particle size in the range between $110 \mu \mathrm{m}$ and $244 \mu \mathrm{m}$ at $1735 \mathrm{~K}$ :

$$
\begin{cases}A=(0.9 \pm 2.5) \times 10^{9} d^{-(2.2 \pm 0.5)}, & \text { for PCR2 } \\ A=(1.4 \pm 5.5) \times 10^{13} d^{-(4.2 \pm 0.8)}, & \text { for PCR } 4^{\prime}\end{cases}
$$

(5) When the reaction is dominated by gas reduction, the reaction rate constant linearly decreased with the increase of $\ln \left[p\left(\mathrm{O}_{2}\right)\right]$ in the reacting gases. The reaction of hematite particles within $70 \mathrm{~ms}$ can be dominated by the thermal decomposition rather than the gas reduction. Furthermore, the reaction rate of thermal decomposition can be accelerated by increasing the radiative properties of the gas mixture, which is introducing high content of $\mathrm{CO}_{2}$ into the gas system. As a result, within the scope of the investigation, the reduction rate of $110 \mu \mathrm{m}$ hematite particles in 95 pct $\mathrm{CO}_{2}$-containing gas is higher than that in the other less $\mathrm{CO}_{2}$-containing gas mixtures.

\section{ACKNOWLEDGMENTS}

This research was carried out under project number T41.5.13489 in the framework of the Research Program of the Materials innovation institute (M2i) (ww w.m2i.nl) supported by the Dutch government. Dr. Dharm Jeet Gavel, Ms. Xiaoling Guo and Mr. Sander Van Asperen from TU Delft and Dr. Yinxia Qu from

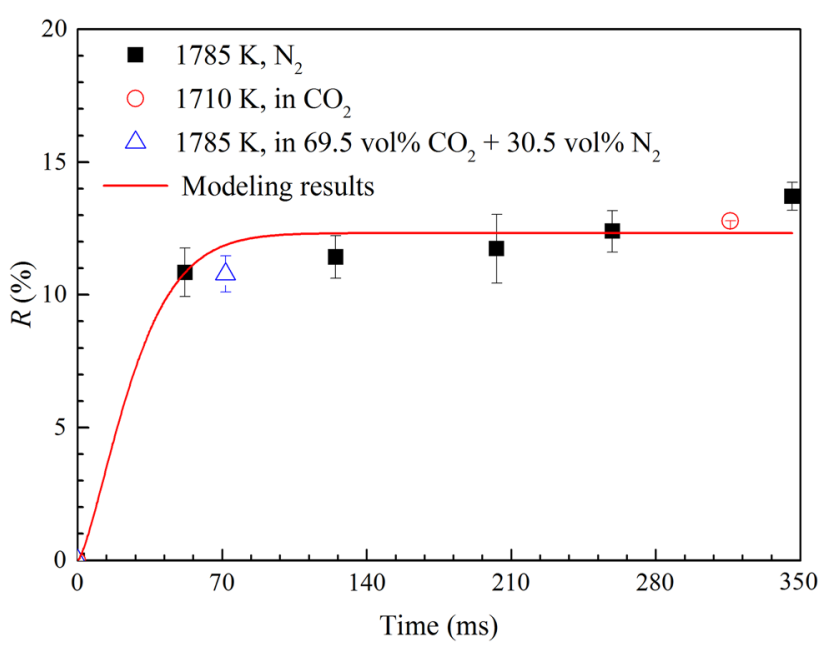

Fig. 10-Thermal decomposition of hematite ore (110 $\mu \mathrm{m}$ particles) in inert gases and a fitting result with JMAK model $(n=1.405$, $k=32.7 \mathrm{~s}^{-1}$ ).

Northeastern University are acknowledged for discussion, gas connection, and assembly of the set-up. We would like to express our thanks to Koen Meijer from Tata Steel Europe (IJmuiden) for fruitful discussions for this study. Mr. Ruud Hendrikx from the Delft University of Technology is acknowledged for X-ray analysis. Mr. Michel van den Brink and Dr. Prakash Venkatesan from TU Delft are acknowledged for ICP-AES analysis. Dr. Chenna Rao Borra from TU Delft are acknowledged for titration analysis.

\section{OPEN ACCESS}

This article is licensed under a Creative Commons Attribution 4.0 International License, which permits use, sharing, adaptation, distribution and reproduction in any medium or format, as long as you give appropriate credit to the original author(s) and the source, provide a link to the Creative Commons licence, and indicate if changes were made. The images or other third party material in this article are included in the article's Creative Commons licence, unless indicated otherwise in a credit line to the material. If material is not included in the article's Creative Commons licence and your intended use is not permitted by statutory regulation or exceeds the permitted use, you will need to obtain permission directly from the copyright holder. To view a copy of this licence, visit http://creativec ommons.org/licenses/by/4.0/.

\section{REFERENCES}

1. H.Y. Sohn: American Iron and Steel Institute Technology Roadmap Program Final Project Report, University of Utah, Salt Lake City, Utah, 2008.

2. H. Sohn: Steel Times Int., 2007, vol. 31, p. 68

3. W.-I. Park and S.-M. Jung: ISIJ Int., 2015, vol. 55, pp. 166-74.

4. L. Guo, J. Gao, Y. Zhong, and Z. Guo: ISIJ Int., 2015, vol. 55, pp. $1806-15$. 
5. D.-Q. Fan, H.Y. Sohn, Y. Mohassab, and M. Elzohiery: Metall. Mater. Trans. B, 2016, vol. 47B, pp. 3489-3500.

6. Y. Qu, Y. Yang, Z. Zou, C. Zeilstra, K. Meijer, and R. Boom: ISIJ Int., 2014, vol. 54, pp. 2196-2205.

7. Y. Qu, Y. Yang, Z. Zou, C. Zeilstra, K. Meijer, and R. Boom: ISIJ Int., 2015, vol. 55, pp. 149-57.

8. Y. Qu, Y. Yang, Z. Zou, C. Zeilstra, K. Meijer, and R. Boom: ISIJ Int., 2015, vol. 55, pp. 952-60.

9. Y. Qu, Y. Yang, Z. Zou, C. Zeilstra, K. Meijer, and R. Boom: Ironmak. Steelmak., 2015, vol. 42, pp. 763-73.

10. Y. Qu: Experimental Study of the Melting and Reduction Behaviour of Ore Used in the HIsarna Process, PhD thesis, Delft University of Technology, Delft, The Netherlands, 2013.

11. Z. Chen, C. Zeilstra, J.v.d. Stel, J. Sietsma and Y. Yang: Metall. Mater. Trans. B, 2021, https://doi.org/10.1007/s11663-021-02173y. Accessed 18 May 2021.

12. K. Barmak: Metall. Mater. Trans. A, 2010, vol. 41A, pp. 2711-75.

13. M. Hillert: Metall. Mater. Trans. A, 2011, vol. 42A, p. 3241.

14. J. William and R. Mehl: Trans. Metall. Soc. AIME, 1939, vol. 135, pp. 416-42.

15. M. Avrami: J. Chem. Phys., 1939, vol. 7, pp. 1103-12.

16. M. Avrami: J. Chem. Phys., 1940, vol. 8, pp. 212-24.

17. M. Avrami: J. Chem. Phys., 1941, vol. 9, pp. 177-84.

18. N.V. Alekseechkin: Condens. Matter Phys., 2008, vol. 11, pp. $597-$ 613.

19. E. Villa and P.R. Rios: Acta Mater., 2010, vol. 58, pp. 2752-68.

20. J. Yu, Y. Han, Y. Li, P. Gao, and W. Li: Minerals, 2017, vol. 7, p. 209.

21. A. Pineau, N. Kanari, and I. Gaballah: Thermochimica acta, 2006, vol. 447, pp. 89-100.

22. F. Chen, Y. Mohassab, S. Zhang, and H.Y. Sohn: Metall. Mater. Trans. B, 2015, vol. 46B, pp. 1716-28.

23. F. Chen, Y. Mohassab, T. Jiang, and H.Y. Sohn: Metall. Mater. Trans. B, 2015, vol. 46B, pp. 1133-45.

24. H. Wang: Reduction kinetics of iron ore concentrate particles relevant to a novel green ironmaking process, Ph.D. Thesis, University of Utah, Salt Lake, USA, 2011.
25. H. Wang and H. Sohn: Metall. Mater. Trans. B, 2013, vol. 44B, pp. $133-45$.

26. B. Abolpour, M.M. Afsahi, A. Soltani Goharrizi, and M. Azizkarimi: Ironmak. Steelmak., 2017, vol. 44, pp. 750-61.

27. M. Elzohiery, D. Fan, Y. Mohassab, and H. Sohn: Ironmak. Steelmak., 2020, pp. 1-8.

28. M. Elzohiery, H.Y. Sohn, and Y. Mohassab: Steel Res. Int., 2017, vol. 88, p. 1600133.

29. A. El-Geassy and M. Nasr: Trans. Iron Steel Inst. Jpn., 1988, vol. 28, pp. $650-58$.

30. J.-M. Pang, P.-M. Guo, Z. Pei, C.-Z. Cao, and D.-W. Zhang: J. Iron Steel Res. Int., 2009, vol. 16, pp. 07-11.

31. P. Pourghahramani and E. Forssberg: Thermochim. Acta, 2007, vol. 454 , pp. $69-77$.

32. H.Y. Sohn and P.C. Chaubal: Metall. Trans. B, 1993, vol. 24B, pp. $975-85$.

33. H. Kobayashi: Devolatilization of pulverized coal at high temperatures, Ph.D. Thesis, Massachusetts Institute of Technology, Cambridge, USA, 1976.

34. E. Takegoshi, Y. Hirasawa, S. Imura, and T. Shimazaki: Int. J. Thermophys., 1984, vol. 5, pp. 219-28.

35. M. Takeda, T. Onishi, S. Nakakubo, and S. Fujimoto: Mater. Trans., 2009, vol. 50, pp. 2242-46.

36. L. Mampel Kurt: Z. Phys. Chem., 1940, vol. 187A, p. 235.

37. D. Fan, Y. Mohassab, M. Elzohiery, and H.Y. Sohn: Metall. Mater. Trans. B, 2016, vol. 47B, pp. 1669-80.

38. J. van de Stel, K. Meijer, C. Teerhuis, C. Zeijlstra, G. Keilman, and $\mathrm{M}$. Ouwehand, in IEAGHG/IETS Iron and Steel Industry CCUS and Process integration workshop, Tokyo, 2013.

39. M. Salmani, E.K. Alamdari, and S. Firoozi: J. Therm. Anal. Calorim., 2017, vol. 128, pp. 1385-90.

40. O.J. Kim and T.H. Song: J. Quant. Spectrosc. Radiat. Transf., 2000, vol. 64, pp. 379-94.

Publisher's Note Springer Nature remains neutral with regard to jurisdictional claims in published maps and institutional affiliations. 